\title{
"DISPUTAR A 'NEGA'": UMA ANÁLISE DA EXPRESSÃO POPULAR NA PERSPECTIVA DOS ESTUDOS DE GÊNERO, DISCURSO, RAÇA' E CLASSE SOCIAL
}

\author{
'DISPUTE THE NEGA': AN ANALYSIS OF THE POPULAR EXPRESSION FROM THE \\ PERSPECTIVE OF STUDIES OF GENDER, SPEECH, \\ RACE AND SOCIAL CLASS
}

\section{Maria Regina de Lima Gonçalves Oliveira* Ariovaldo Lopes Pereira**}

\section{RESUMO}

Este artigo objetiva discutir a expressão "disputar a "nega" - que integra o universo cultural de muitas regiões do Brasil e constitui práticas sociais em contextos de competição em jogos diversos - na perspectiva dos estudos de gênero, discurso, raça e classe social. Para tanto, nos aportamos teoricamente em autoras e autores que problematizam as relações de gênero de forma interseccional, destacando outras dimensões que perpassam essa categoria, tais como raça, classe, sexualidade, etnia etc. São trazidos à cena teórica os estudos de Angela Davis (2016) e Heleieth Saffioti (2013) sobre gênero, raça e classe e os apontamentos de Norman Fairclough $(1998 ;$ 2001; 2003) sobre discurso, dentre outros. Intentamos, com isso, usando como ferramenta de análise os princípios da Análise de Discurso Crítica - ADC (FAIRCLOUGH, 2001, 2003; VIEIRA; RESENDE, 2016; MAGALHÃES, 2000), descortinar os discursos ideológicos que subjazem à expressão "disputar a 'nega", bem como compreender sua raiz cultural e histórica, haja vista que a pessoa que é objeto da disputa é uma mulher negra cujo corpo é oferecido como prêmio ao vencedor, sendo, assim, objetificado, subalternizado e instrumentalizado, seguindo a lógica de uma sociedade patriarcal em que o corpo da mulher, e da mulher negra em especial, é usado primordial e essencialmente para servir ao homem em suas necessidades físicas e emocionais. Neste estudo, nos pautamos na concepção butleriana de gênero, por concordarmos que a constituição dessa categoria se dá mediante os confrontos culturais e sociais reiterados cotidianamente pelas práticas discursivas. Em outras palavras, trata-se da preponderância do discurso na constituição dos sujeitos, dado que nos constituímos a partir da outra, do outro. Ao propormos o estudo da expressão em ênfase, na perspectiva da análise interseccional (SCOTT, 1994; BUTLER, 2016; DAVIS, 2016), percebemos que a interseccionalidade de gênero, permeada por outros marcadores sociais, evidencia a subalternização feminina, visto que a categoria mulher, sobretudo a negra e pobre, permanece, ainda nos dias atuais, em condição de objetificação, marginalização e subalternização na sociedade.

Palavras-chave: "disputar a 'nega", gênero; raça; classe, discursos.

\section{ABSTRACT}

This article aims to discuss the expression 'dispute the nega' - which is part of the cultural universe of many regions of Brazil and constitutes social practices in contexts of competition in different games - from the perspective of studies of gender, discourse, race and social class. For this purpose, we theoretically focus on authors who problematize gender relations in an intersectional perspective, highlighting other dimensions that permeate this category, such as race, class, sexuality, ethnicity, etc. The studies of Angela Davis (2016) and Heleieth Saffioti (2013) on gender, race and class, and Norman Fairclough's (1998; 2001; 2003) works on discourse, among others, are brought to the theoretical scene. We intend, with this, using as a tool of analysis the principles of Critical Discourse Analysis - ADC (FAIRCLOUGH, 2001, 2003; VIEIRA; RESENDE, 2016; MAGALHÃES, 2000), to unveil the ideological discourses that underlie the expression 'dispute the nega', as well as understand its cultural and historical roots, once the person who is the object of the dispute is a black woman whose body is offered as a prize to the winner, thus being objectified, subordinated and instrumentalized, following the logic of a patriarchal society in which the woman's body, and the black woman's in particular, is used primarily and essentially to serve men in their physical and emotional needs. In this study, we are guided by the butlerian conception of gender, as we agree that the constitution of this category occurs through cultural and social confrontations reiterated daily by discursive practices. In other words, it is about the preponderance of the discourse in the constitution of the subjects, given that we are constituted from the other. When proposing the study of expression in emphasis in the perspective of intersectional analysis (SCOTT, 1994; BUTLER, 2016; DAVIS, 2016) we realize that the intersectionality of gender permeated by other social markers puts on evidence female subordination, since the category woman, especially the black and poor, remains, even today, in a condition of objectification, marginalization and subordination in society. Keywords: 'dispute the nega'; genre; race; class; discourses.

* Universidade Estadual de Goiás (UEG),Anápolis, GO, Brasil. mariareginalima91@hotmail.com Orcid: https://orcid.org/0000-0001-6774-8417

** Universidade Estadual de Goiás (UEG), Anápolis, GO, Brasil. arylopes_br@yahoo.com Orcid: https://orcid.org/0000-0001-5626-664X

1. Trabalhamos com a categoria "raça" de forma semelhante à compreensão de Ochy Curiel (2009, p.1), o qual a entende como "a construção simbólica, cultural, e sobretudo política, que tem feito do biológico, estratégia onde sustenta o racismo". 


\section{CONSIDERAÇÕES INICIAIS}

Neste artigo, propomo-nos a analisar criticamente a expressão "disputar a 'nega'" na perspectiva dos estudos de gênero, discurso, raça e classe social. Para tanto, alinhamos o estudo aos pressupostos pós-estruturalistas (BUTLER, 2016; SCOTT, 1990; 1994) os quais problematizam as identidades universais de gênero e compreendem essa categoria como perpassada por outros marcadores sociais como raça, classe, sexualidade, etnia etc., bem como aos princípios da Análise de Discurso Crítica (ADC) proposta, entre outros, pelo teórico Norman Fairclough (2001; 2003).

Situamos nossa compreensão de gênero nos limiares do feminismo pós-estruturalista fundamentado, sobretudo, nas teorizações de Joan $\mathrm{Scott}^{2}$ e Judith Butler no que concerne às questões históricas como constituintes dessa categoria social, aos aspectos discursivos e sua preponderância na reiteração de hierarquias. Para Joan Scott (1998, p.15), gênero "não se relaciona simplesmente às ideias, mas também às instituições, às estruturas, às práticas cotidianas como os rituais, e tudo o que constitui as relações sociais" e, nesse sentido, "o discurso é o instrumento de entrada na ordem do mundo e, mesmo não sendo anterior à organização social, é dela inseparável".

As percepções da vertente proposta aqui nos permite problematizar as questões de gênero com base na centralidade da linguagem, o que significa dizer que o conceito de gênero se vincula igualmente aos aspectos sociais, culturais e linguísticos. Diante disso, nossa preocupação se assenta no anseio de compreender as implicações do discurso enquanto poder, haja vista que ele se relaciona às estruturas sociais ${ }^{3}$ e, conforme nos situa Teun Van Dijk (2015), o poder social está intimamente relacionado ao controle, isto é, "controle de um grupo sobre outros grupos e seus membros" (p.17).

Certamente há, na expressão "disputar a 'nega", discursos velados que remontam, de certa forma, à história da mulher negra e sua subalternização, subjugação e coisificação em relação ao homem, em especial ao homem branco - condição que também se estende à mulher branca, porém, sem a carga da inferioridade racial - e evidenciam disparidades de gênero, raça e classe ainda instanciadas na sociedade, uma vez que esse enunciado é recorrente em discursos cotidianos em diversos contextos sociais na atualidade. Preocupando-nos com a produção e, mais especificamente, com a reprodução e os efeitos desse enunciado discursivo, questionamos o contexto social/cultural que deu origem a ele, bem como os discursos ideológicos que o circundam.

\section{ADC: PROBLEMATIZANDO PODER E IDEOLOGIA}

[...] O discurso contribui para a construção de identidades sociais ou posições de sujeito; [...] o discurso constrói relações sociais; [...] o discurso contribui para a construção dos sistemas de conhecimentos e crenças. (FAIRCLOUGH, 2001 p. 64)

Ao citar os efeitos constitutivos do discurso propostos por Norman Fairclough (2001, 2003), pretendemos ilustrar, igualmente, em primeiro plano, que esses efeitos não são visíveis a todas as pessoas, ou seja, são discursos invisíveis que permeiam e, simultaneamente, (trans)formam a sociedade. Em segundo plano, queremos mostrar que a ADC, contrariamente a outras vertentes mais tradicionalistas, não percebe a linguagem como desvinculada da sociedade ${ }^{4}$, mas como parte indissociável dela, pois, conforme nos informam Viviane Vieira e Viviane de Melo Resende (2016, p. 14), a "Análise de Discurso Crítica, em um sentido amplo, refere-se a um conjunto de abordagens científicas interdisciplinares para estudos críticos da linguagem como prática social".

Nessa direção, a linguagem torna-se parte inseparável da vida social, o que nos permite pressupor que há uma relação dialética entre a díade linguagem e sociedade (FAIRCLOUGH, 2001, 2003), o que, nas palavras de Maria

2. Para autora, em um de seus textos mais citados no âmbito acadêmico, "[g]ênero é um elemento constitutivo de relações sociais fundadas sobre as diferenças percebidas entre os sexos e o gênero é um primeiro modo de dar significado às relações de poder" (SCOTT, 1990 p.14).

3. Norman Fairclough $(2001,2003)$ concebe essa relação como dialética, pois para ele o discurso é moldado pela estrutura social, ao passo que é também parte dessa mesma estrutura.

4. Em Discurso e mudança social (2001), Norman Fairclough fala sobre o conceito de discurso na vertente da ADC: "Ao usar o termo 'discurso', proponho considerar o uso da linguagem como forma de prática social e não como atividade puramente individual ou reflexo de variáveis institucionais. Isso tem várias implicações. Primeiro, implica ser o discurso um modo de ação, uma forma em que as pessoas podem agir sobre o mundo e especialmente sobre os outros, como também um modo de representação. [...] Segundo, implica uma relação dialética entre o discurso e a estrutura social, existindo mais geralmente tal relação entre a prática social e a estrutura social: a última é tanto uma condição como um efeito da primeira" (p. 90-91). 
Cecília de Lima (2014, p. 65), significa dizer que "o discurso molda a sociedade e também é moldado por ela por meio de relações de classe, gênero, raça ou por contextos e instituições [...]".

Entender o discurso como campo multidisciplinar no qual a relação entre o texto, o contexto e a interação entre os sujeitos envolvidos se dá dialeticamente, possibilita pensar o texto para além das informações nele veiculadas, considerando também as condições de produção, interpretação e consumo, bem como o poder intrínseco ao discurso e aos enunciados.

Sob enfoque da ADC a preocupação se centra, principalmente, na desmistificação dos aspectos ideológicos subjacentes ao discurso e, mais precisamente, nos efeitos de sentidos dos textos "sobre as relações sociais, ações e interações, conhecimentos, crenças, atitudes, valores, identidades" (VIEIRA, RESENDE, 2016 p. 25). O foco da análise do discurso concebido como prática social está em desvelar, sobretudo, as questões de ideologia e poder (LIMA, 2014). Isso implica dizer, conforme pontua Izabel Magalhães (2000, p. 92), que na prática social são considerados "três aspectos principais: o econômico, o político - ligado às noções de poder e ideologia - e o cultural - ligado a valores e identidades culturais".

Ancorando-se nos estudos de Norman Fairclough (2001, 2003), Maria Aparecida Resende Ottoni (2014) expressa sua compreensão de que a ADC se interessa, primeiramente, pela relação entre linguagem e poder, pois seu objetivo principal está centrado na desmistificação das ideologias subjacentes ao discurso que institui verdades acerca de questões sociais amplas tais como gênero, raça, classe e etnia. Segundo Viviane Vieira e Viviane de Melo Resende (2016, p. 27), na ADC a ideologia é concebida como um "instrumento semiótico de lutas de poder", isto é, como uma das formas encontradas pelos grupos dominantes para manter sua hegemonia de modo que ela pareça ser a "única possível e legítima". Corroborando essa ótica, John Brookshire Thompson (2002, p. 77) afirma que os aspectos ideológicos inerentes ao texto servem para "estabelecer e sustentar relações de dominação".

Dessa forma, pode-se deduzir que, ao se preocupar com os sujeitos envoltos/permeados pelo discurso, essa vertente crítica aponta para as possibilidades de desvencilhamento, emancipação e, consequentemente, transformação social, pois, conforme afirma Carlos Gouveia (1997, p. 339), a linguagem, por fazer parte da sociedade e ser considerada uma prática social, "é um dos mecanismos pelos quais a sociedade se reproduz e autorregula". Assim, ao propor o desvencilhamento desse controle a partir da análise dos aspectos ideológicos intrínsecos ao discurso, a ADC possibilita a "apoderação social de grupos dominados" (VAN DIJK, 2015 p. 13). Em outras palavras, da mesma forma que o discurso institui desigualdades, ele é também o instrumento capaz de desconstruí-las (FAIRCLOUGH, 2001).

\section{GÊNERO E INTERSECÇÕES DE RAÇA E CLASSE}

Dado às problematizações concernentes à compreensão da categoria mulher a partir de sua universalização e essencialização, a qual, de certa forma, nega a existência de outros marcadores sociais como mulheres negras, pobres e lésbicas, por exemplo, a interseccionalidade critica, segundo Elsa Dorlin (2009), a forma com a qual os movimentos feministas e antirracistas têm se portado diante de tais questões. De acordo com a autora, a proposta interseccional "tenta mostrar como os dispositivos legais de luta contra as discriminações reificam as categorias exclusivas, tais que 'sexo' ou 'raça' ou 'classe"' (p. 9).

Diante disso, a preocupação está centrada na crítica à universalização do termo mulher, já que as problemáticas de raça, classe, sexualidade, etnia etc. perpassam essa categoria, bem como na percepção de que, ao se pretenderem universais/neutros, os movimentos feministas acabam por reificar e apagar outras minorias sociais (DORLIN, 2009).

Lélia Gonzales (1984), ao propor discussões sobre racismo e sexismo, evidencia o quanto essas categorias estão imbricadas. Para ela, trata-se de um "duplo fenômeno" que de forma articulada "produz efeitos violentos sobre a mulher negra em particular" (p. 224). Com efeito, as discrepâncias de gênero se fazem ainda mais presentes na vida da mulher negra, pois ela é, nesse contexto, duas vezes invisibilizada - por sua condição de mulher e por sua raça (DAVIS, 2016).

Ao discutir sobre esse processo de supressão, Sueli Carneiro (2003) aponta para a necessidade de se pensar na interseccionalidade das categorias gênero, raça e classe, pois, segundo a autora, ao pretender agir "em conformidade com outros movimentos sociais progressistas da sociedade brasileira, o feminismo esteve, também, por longo tempo, prisioneiro da visão eurocêntrica e universalizante das mulheres". Em decorrência disso, há ainda, nos dias atuais, uma dificuldade em "reconhecer as diferenças e desigualdades presentes no universo feminino" e, com isso, "as vozes silenciadas e os corpos estigmatizados de mulheres vítimas de outras formas de opressão além do sexismo" continuam "no silêncio e na invisibilidade" (p. 118). 
Dessa forma, ao pensarmos a categoria mulher perpassada pelas questões de raça, percebemos as implicações do período escravocrata e seus ranços na organização social do Brasil de hoje. A partir dessa percepção, se desencadeia a ideia de que pensar gênero e raça (e, consequentemente, classe) é remontar, de certa forma, aos aspectos históricos e culturais que culminaram no silenciamento e na supressão da mulher negra (CARNEIRO, 2003).

De acordo com Roger Bastide e Florestan Fernandes (1959, p. 83) "a alienação social da pessoa do negro se processou inicialmente como alienação social da pessoa do escravo", o que significa dizer que, dado à sua condição de mercadoria, cabia aos negros ${ }^{5}$ serem apenas ferramentas de trabalho ou, em outro termo - uma 'coisa'. Entretanto, ao analisar a posição social da mulher sob essa ordem, Heleieth Saffioti (2013) esclarece que, embora os brancos negassem a condição humana do homem negro, sua coisificação não foi total ${ }^{6}$, dado que eram, em certa medida, valorizados em suas funções no processo produtivo. Assim, seguindo os interesses capitalistas dos senhores, a mulher negra, como nos situa Heleieth Saffioti (2013), era duplamente explorada, pois "cabia à escrava, além de sua função no sistema produtivo de bens e serviços, um papel sexual, via de uma maior reificação e, simultaneamente, linha condutora do desvendamento do verdadeiro fundamento da sociedade de castas" (p. 236).

Nesse sentido, a dupla exploração da mulher negra "tornava-a, pois, simultaneamente res ${ }^{7}$ e pessoa humana" (SAFFIOTI, 2013 p. 236). Assim, ela oscilava entre o trabalho produtivo e o papel sexual - que podemos chamar, sem risco de anacronismos, de estupro. Seu corpo destituído de vontade própria servia, portanto, aos interesses tanto capitalistas (classe e raça) quanto sexuais dos seus senhores (gênero e raça), aspectos que a colocam numa condição de vulnerabilidade e subserviência bem maior do que a dos homens negros (DAVIS, 2016).

Assim, observamos que o período colonial perpetuou discursos que concebem o corpo negro como objeto de desejo e instrumento de trabalho, conforme apontamentos dos estudiosos Joaze Bernardino-Costa e Ramón Grosfoguel (2016) que coadunam com a visão de bell hooks (1995).

No discurso colonial, o corpo colonizado foi visto como corpo destituído de vontade, subjetividade, pronto para servir e destituído de voz (hooks, 1995). Corpos destituídos de alma, em que o homem colonizado foi reduzido a mão de obra, enquanto a mulher colonizada tornou-se objeto de uma economia de prazer e do desejo. (BERNARDINO-COSTA; GROSFOGUEL, 2016, p. 19)

\section{3. "DISPUTAR A 'NEGA'": CONTEXTO HISTÓRICO-CULTURAL E IDEOLÓGICO}

A história do Brasil se divide em Colônia, Império e República. Nossa discussão, como visto, se situa nos dois primeiros períodos, mais precisamente no período colonial ${ }^{8}$, uma vez que desse contexto histórico ecoam discursos que reificam a mulher negra e a colocam, ainda nos dias atuais, em situação maior de subalternização e subserviência do que as mulheres brancas, por exemplo, e os homens - sobretudo os brancos - em condição permanente de dominadores ${ }^{9}$.

Contextualizando o enunciado que elegemos como nosso objeto de análise neste artigo, é comum, em muitos contextos brasileiros, o uso da expressão "disputar a 'nega" em situações nas quais há um empate em algum tipo de jogo e os competidores (predominantemente homens) buscam o desempate. Assim, a expressão é uma alusão à partida final que indicará o vencedor do jogo. Diante disso, podemos situar o contexto histórico e cultural dessa expressão aos meandros do período escravocrata, haja vista que quem está em disputa é uma mulher negra, a qual é reificada exatamente nesse período, sendo vista apenas como uma "coisa", um bem do qual seu dono poderia dispor da maneira que quisesse (SAFFIOTI, 2013; DAVIS, 2016).

Heleieth Saffioti (2013) afirma que, pelo fato da escravidão, para a mulher negra, representar uma articulação entre a prestação de serviços ao sistema produtivo e a prestação de serviços sexuais ${ }^{10}$ aos seus senbores brancos, ela se converteu em "instrumento inconsciente que, paulatinamente, minava a ordem estabelecida, quer na sua dimensão

5. Nos referimos aqui apenas aos homens.

6. Não pretendemos, com essa afirmação, "romantizar a escravidão", haja vista que "a maior valorização do escravo artífice representa muito mais o meio adequado para o atingimento dos fins econômicos do senbor do que uma vinculação de caráter efetivo" (SAFFIOTI, 2013 p.235).

7. Heleieth Saffioti (2013) utiliza o termo res como sinônimo de bem, propriedade, coisa etc.

8. Isso porque no Brasil as/os negras/os começaram a ser escravizadas/os exatamente quando o país "se tornou" colônia de Portugal.

9. Ao situarmos nosso estudo nos dois primeiros períodos - colonial e imperial - não estamos negando a existência de discursos que coisificam a mulher no período republicano, e até mesmo a existência da escravidão camuflada, pois reconhecemos que as questões de gênero, raça e classe não foram "resolvidas" com a República.

10. Como se sabe, essa prestação de serviços sexuais era, na verdade, uma violação do corpo da mulher, um estupro. Mas como ela era vista na época como mercadoria e, por essa condição, uma coisa destituída de sentimentos, o ato não era considerado violação, mas uma prática comum entre os donos de escravas. 
econômica, quer na sua dimensão familiar" (p. 238). Em outras palavras, em virtude da valorização sexual da mulher negra como objeto de sua satisfação, seu dono assumia posições antieconômicas, tais como "a venda e a tortura de negros com os quais aquele competia no terreno amoroso"1" (SAFFIOTI, 2013 p. 238).

Assim, portanto, a "nega" era disputada não apenas pelos senhores brancos, pois a concorrência também ocorria entre eles o os homens negros. Estabelecia-se, ainda, segundo Heleieth Saffioti (2013, p. 238), uma desordem, visto que

[a]s relações sexuais entre os senhores e escravas desencadeavam, por mais primárias e animais que fossem, processos de interação social incongruentes com as expectativas de comportamento que presidiam à estratificação em castas. Assim, não apenas homens brancos e negros se tornavam concorrentes na disputa das negras, mas também mulheres brancas e negras disputavam a atenção do homem branco. Evidentemente, a rivalidade entre brancas e negras não se configurava totalmente como uma competição.

Cabia às negras manter uma relação amistosa com seus senhores, de tal forma que muitas se destinavam, quase que exclusivamente, a satisfazer as necessidades sexuais deles. Às brancas era reservada a função "nobre" de esposa e mãe dos/as filhos/as legítimos/as, enquanto que às negras restava o papel de meras reprodutoras de mais escravos e escravas que lhes serviriam.

Entretanto, a relação sexual advinda desse contexto não era vista apenas como uma forma de se "aproveitar" a mercadoria; era também uma forma de punição às mulheres que violassem alguma regra do seu senhor. Angela Davis (2016), ao abordar o período escravocrata, constata que

Como mulheres, as escravas eram inerentemente vulneráveis a todas as formas de coerção sexual. Enquanto as punições mais violentas impostas aos homens consistiam em açoitamentos e mutilações, as mulheres eram açoitadas, mutiladas e também estupradas. O estupro, na verdade, era uma expressão ostensiva do domínio econômico do proprietário e do controle do feitor sobre as mulheres negras na condição de trabalhadoras. (DAVIS, 2016, p. 20)

Nessa direção, a "nega" era sempre silenciada e destituída de vontades, servindo somente aos interesses dos brancos. A expressão "disputar a 'nega"" tem raízes que remetem a esse período histórico, dado que, além do exposto, as mulheres negras escravizadas eram disputadas nos momentos de jogos e descontração, tornando-se o prêmio daqueles que ganhavam a partida. Isto significa dizer que elas eram objetos sexuais dos ganhadores, o seu 'troféu' e, por essas condições, poderiam ser usadas da forma que os senhores julgassem mais conveniente.

Os discursos de dominação, outrora representados na imagem do colonizador (senhores brancos) e atualmente reproduzidos em sociedades de bases patriarcais - sobretudo em sua corrente dominante branca, classes média e alta e cis-heteronormativa - perpassam a representação da mulher e, em decorrência disso, a objetificam ${ }^{12}$ (LEITÃO, 1988) ou, nas palavras de Heleieth Saffioti (2013), a reificam. Assim, os discursos ideológicos veiculados socialmente corroboram a ideia de coisificação da mulher, tanto no período escravocrata quanto nos dias atuais.

Com base na concepção de ideologia como "instrumento semiótico de lutas de poder" (VIEIRA; RESENDE, 2016, p. 27), podemos dizer que a expressão "disputar a "nega" é uma forma de hierarquização e os aspectos ideológicos que a circundam, uma estratégia encontrada pelos grupos dominantes para manter sua hegemonia de modo que ela pareça ser a "única possível e legítima". Há, nesse sentido, um processo de legitimação que objetiva tanto estabelecer quanto sustentar relações de dominação.

\section{OS EFEITOS DISCURSIVOS DA EXPRESSÃO “DISPUTAR A 'NEGA'”}

Como mencionado neste artigo, ao alinharmos nossa percepção de gênero aos princípios pós-estruturalistas, pretendemos problematizar as questões de gênero com base na centralidade da linguagem. Isso significa dizer que entendemos essa categoria como um "construto sociocultural e linguístico, produto e efeito das relações de poder" (MEYER, 2013, p. 18). Outrossim, concordamos com a concepção de Judith Butler (1998, p. 30) de que o sujeito é constituído discursivamente "mediante atos de diferenciação que o distinguem de seu exterior constitutivo" e, sendo assim, o sujeito é contingente e político.

11. Diríamos aqui, "no terreno sexual", uma vez que as mulheres negras eram consideradas apenas mercadorias, indignas, portanto, de fazer parte da família de um homem branco e rico, bem como eram consideradas objetos sexuais e não mulheres "para se apaixonar".

12. De acordo com Eliane Vasconcellos Leitão (1988, p. 28), "a desumanização da mulher faz-se primeiramente quando o homem a considera um objeto que tem de ser bonito para poder ocupar um lugar na sociedade. [...] O homem não a vê como um ser humano, e sim como um objeto sexual, com características físicas que lhe devem agradar. Isso ocorre porque nossa sociedade foi criada pelos homens e, até bem pouco tempo atrás, era dirigida exclusivamente por eles". 
Diante disso, e considerando o período histórico que originou a expressão "disputar a 'nega'", percebemos os modos de operação da ideologia, visto que há, de certa forma, uma instituição de verdades tanto para legitimar quanto para sustentar a dominação de um grupo sobre outro (brancos sobre negros e negras, por exemplo). Maria Cecília de Lima (2014), ao citar John Brookshire Thompson (1995), descreve os modos de operação da ideologia, a qual serve à

legitimação, dissimulação, unificação, fragmentação e reificação - que naturalizam relações desiguais; entre elas, as de gênero social, pois a ideologia serve de recurso para suavizar a imposição social, justificando a dominação/subordinação da classe hegemônica que luta para manter sua posição sempre instável. (p. 66)

A ideologia patriarcal de base colonial opera de modo a justificar a dominação dos homens e a subordinação das mulheres, sobretudo a subjugação instituída por homens brancos às mulheres negras. Esses discursos ideológicos incidem, principalmente, na regulação/controle/violação do corpo da mulher negra, uma vez que ele é visto como destituído de vontade própria, conforme discutido na seção anterior.

De acordo com Nilma Lino Gomes (2017), no contexto escravocrata brasileiro o corpo negro estava imerso em um estado de ignorância, dado que ele era escravizado e violado sem nenhum direito. Nos dias atuais o corpo negro carrega ainda uma pesada carga de regulação, pois sua possível emancipação é construída no "contexto de uma sociedade regulada não só pelo capitalismo, mas também pelo racismo e pelo machismo" (p. 98).

Nesse sentido, o desvencilhamento dessa carga ideológica da mulher negra como objeto e ser inferior ao homem, especialmente ao homem branco, é ainda mais pesado e difícil de se concretizar, já que "o racismo constituise um sistema de dominação e opressão estrutural pautado numa racionalidade que hierarquiza grupos e povos baseada na crença da superioridade e inferioridade racial" (GOMES, 2017 p. 98). Em outros termos, a mulher negra é inferior tanto por sua raça - em relação ao grupo dominante branco, composto por homens e mulheres - quanto por seu gênero - em relação ao grupo dominante branco ou negro, composto por homens.

Com isso, vemos na expressão "disputar a "nega" a materialização de um discurso sexista e misógino, o qual objetifica e subalterniza a mulher, reduzindo-a ao "status de coisa" (LEITÃO, 1988 p. 27), bem como se imbrica às questões de poder entre aquele que domina e aquela que é dominada. Sobre o poder inerente ao discurso, Norman Fairclough (2001, p. 108) assevera que "alguns textos conduzem a guerras ou à destruição de armas nucleares; outros levam as pessoas a perder o emprego ou a obtê-lo; outros, ainda, modificam as atitudes, as crenças ou as práticas das pessoas". Dessa forma, ao enunciar uma disputa da mulher negra, está-se, de forma (nem tanto) velada, reiterando a condição de subserviência da mulher estabelecida no período escravocrata e, simultaneamente, apontando o lugar que ela ocupa na sociedade ainda hoje. Institui-se, assim, a legitimação e sustentação do poder do homem branco, pois é ele que 'disputa' e é ele quem 'ganha' a 'nega'.

Ao reproduzir o discurso de disputa da 'nega' nas condições ditas acima - partida final de um jogo, no qual ambos os competidores estão empatados - há uma propagação discursiva (não) intencional (?) que acena à subalternidade da mulher negra. De acordo com Norman Fairclough (1989, p. 85), "a ideologia é mais efetiva quando sua ação é menos visível", ou seja, para a sustentação das assimetrias de poder - representadas na superioridade do homem branco - é essencial que os sujeitos permaneçam "sem consciência" das desigualdades produzidas e reproduzidas discursivamente, pois

Se alguém se torna consciente de que um determinado aspecto do senso comum sustenta desigualdades de poder em detrimento de si próprio, aquele aspecto deixa de ser senso comum e pode perder a potencialidade de sustentar desigualdades de poder, isto é, de funcionar ideologicamente. (FAIRCLOUGH, 1989 p. 85)

Os papéis e posições a serem assumidos por mulheres e homens são instituídos discursivamente e, uma vez que eles são "marcados por relações assimétricas nas quais as identidades são estruturadas, mantendo ou reproduzindo práticas sociais não questionadas, por estarem naturalizadas no grupo e vistas como relações pré-definidas de senso comum e, portanto, imutáveis" (OTTONI, 2014 p. 39), se faz fundamental a percepção das relações de gênero como constituições não estanques, bem como a problematização das minorias sociais inerentes a cada categoria. Entretanto, isso só será possível, nos termos de Norman Fairclough (2001), caso haja uma mudança discursiva a qual pode, ainda segundo Maria Aparecida Resende Ottoni (2014, p. 39), "provocar uma mudança social, transformando as práticas sociais no interior da sociedade". 
Assim, entendemos que o discurso pode tanto instituir quanto questionar as desigualdades sociais. Ele pode tanto produzir/reproduzir/reiterar a sujeição das mulheres (negras) quanto questionar/denunciar/contestar a dominação do homem (branco). Em outras palavras, a expressão "disputar a 'nega" pode ser confrontada e banida dos contextos socioculturais em que é usada, desde que os sujeitos que a enunciam e/ou a presenciam tomem consciência da carga ideológica de cunho racista e sexista que o enunciado carrega e das implicações políticas, sociais e culturais que ele suscita.

\section{CONSIDERAÇÕES FINAIS}

Com base no estudo realizado, podemos depreender, assim como enfatiza Norman Fairclough (1989, 2001, 2003), que a linguagem é parte inseparável da vida social e que, por isso, há uma relação dialética entre linguagem e sociedade. Isto significa dizer, nas palavras de Maria Cecília de Lima (2014, p. 65), que "o discurso molda a sociedade e também é moldado por ela por meio de relações de classe, gênero, raça ou por contextos e instituições $[\ldots]^{\prime \prime}$, relações estas que entendemos se fundamentar em relações de poder que se perpetuam por meio de discursos ideológicos disseminados, legitimados e sancionados na sociedade.

Com isso, percebemos que é por meio dos mecanismos discursivos que as práticas sociais são estabelecidas, uma vez que esse elemento constitui-se e constrói-se pela realidade à qual se vincula, ou seja, "como o discurso se processa na interação, nele recai todo o peso da produção social, e, por isso, ele é considerado como o principal mediador da construção social" (FREITAS, PINHEIRO, 2013, p. 32).

Entendendo, portanto, as relações de gênero, raça e classe como constituídas e constituintes de/por práticas discursivas, vemos no enunciado "disputar a 'nega" a naturalização de discursos que acenam para as desigualdades de gênero, raça e classe, bem como para a propagação da cultura do estupro e de outras formas de violência contra a mulher, fortalecendo e legitimando tais práticas. Percebemos que, ao se propor uma disputa cujo prêmio ao vencedor é uma mulher negra, se está reiterando a situação de subserviência da mulher ao homem e, sobretudo, a naturalização de práticas de violação do corpo da mulher negra pelo homem branco. Há, de forma mais ou menos velada, uma apologia ao estupro e, consequentemente, uma 'coisificação' da mulher pela objetificação de seu corpo.

Conforme afirma Sueli Carneiro (1995), é exatamente a prática de abuso sexual que funda o mito da democracia racial no Brasil, pois o "[e]stupro colonial da mulher negra pelo homem branco no passado e a miscigenação daí decorrente criaram as bases para a fundação do mito da cordialidade e democracia racial brasileira" (p. 546). Diante disso, cria-se um processo de romantização e naturalização da violação do corpo da mulher negra: ela era objeto no período escravocrata e os ranços desse período ainda perpassam os dias atuais.

Com tudo isso notamos que, com o desvelamento dos discursos ideológicos, podemos alcançar o desvencilhamento a essa naturalização/romantização, pois ao nos ancorarmos na análise de discurso como prática social, instantaneamente estamos problematizando as relações de poder, as causas e efeitos destas na sociedade e vice-versa.

Considerando o que Joan Scott (1998, p. 15) expressa ao asseverar que gênero "não se relaciona simplesmente às ideias, mas também às instituições, às estruturas, às práticas cotidianas como os rituais, e tudo o que constitui as relações sociais", e a partir do estudo empreendido aqui, depreendemos que a expressão "disputar a 'nega" se relaciona com a estrutura social da qual se originou e, com isso, reproduz relações de poder assimétricas, injustas e desiguais que permeiam as relações sociais de gênero, raça e classe social.

Em suma, a partir da análise do enunciado "disputar a 'nega" podemos apreender a organização social de sua gênese, bem como os discursos ideológicos que o subjazem. Igualmente, por meio da análise interseccional (SCOTT, 1994; BUTLER, 2016; DAVIS, 2016), percebemos que a categoria gênero permeada por outros marcadores sociais permite evidenciar a subalternização feminina, visto que a categoria mulher, sobretudo a negra e pobre, permanece, ainda nos dias atuais, sendo subalternizada, marginalizada e objetificada na sociedade. 


\section{REFERÊNCIAS}

BASTIDE, Roger; FERNANDES, Florestan. Brancos e negros em São Paulo. São Paulo: Companhia Editora Nacional, 1959.

BERNARDINO-COSTA, Joaze; GROSFOGUEL, Ramón. Decolonialidade e perspectiva negra. Revista Sociedade e Estado, Vol. 31, N. 1, p. 15-24, Janeiro/Abril 2016.

BUTLER, Judith. Fundamentos contingentes: o feminismo e a questão do 'pós-modernismo'. Cadernos Pagu, n. 11, p. 11-42, 1998.

BUTLER, Judith. Problemas de gênero: feminismo e subversão da identidade. Tradução de Renato Aguiar. Rio de Janeiro: Editora Civilização Brasileira, 2016.

CARNEIRO, Sueli. Gênero, raça e ascensão social. Revista Estudos Feministas, v. 3, n. 2, p. 544-552, 2. sem. 1995.

CARNEIRO, Sueli. Mulheres em movimento. Estudos avançados, 17 (49), 2003.

CURIEL, Ochy. Identidades esencialistas o construcción de identidades políticas: El dilema de las feministas afrodescendientes. Revista electrónica Construyendo Nuestra Iterculturalidad, ano 5, v.4, n.5, 2009.

DAVIS, Angela. Mulberes, raça e classe. Tradução de Heci Regina Candiani. São Paulo: Boitempo, 2016.

DORLIN, Elsa. Sexe, race, classe, pour une épistémologie de La dommination. Paris: PUF, 2009.

FAIRCLOUGH, Norman. Language and Power. New York: Longman, 1989.

FAIRCLOUGH, Norman. Discurso e mudança social. Tradução de Izabel Magalhães. Brasília: UNB, 2001 [1992].

FAIRCLOUGH, Norman. Analysing discourse. Textual analysis for social research. London: Routledge, 2003.

FANON, Frantz. Pele negra, máscaras brancas. Tradução de Renato da Silveira. Salvador: EDUFBA, 2008.

FREITAS, Lúcia; PINHEIRO, Veralúcia. Violência de gênero, linguagem e direito - análise de discurso na Lei Maria da Penha. JundiaíSP: Paco Editorial: 2013.

GOMES, Nilma Lino. O movimento negro educador - saberes construídos nas lutas por emancipação. Petrópolis, RJ: Vozes, 2017.

GONZALES, Lélia. Racismo e sexismo na cultura brasileira. In: Revista Ciências Sociais Hoje, Anpocs, 1984, p. 223-244.

GOUVEIA, Carlos. Análise crítica do discurso: enquadramento histórico. In: PEDRO, E. R. (Org.). Análise crítica do discurso: uma perspectiva sociopolítica e funcional. Lisboa: Editorial Caminho, 1997. p.339-356.

HOOKS, bell. Intelectuais negras. Estudos Feministas, v. 3, n. 2, p. 464-469, 1995.

LEITÃO, Eliane Vasconcellos. A mulher na língua do povo. Belo Horizonte: Itatiaia, 1988.

LIMA, Maria Cecília de. Discursos sobre gênero e identidade. In: OTTONI, M. A. R, LIMA, M. C. de (Org.). Discursos, identidades e letramentos - abordagens da Análise de Discurso Crítica. São Paulo: Cortez, 2014.

LOURO, Guacira Lopes. Gênero, sexualidade e educação - uma perspectiva pós-estruturalista. Petrópolis: Vozes, 2014.

MAGALHÃES, Izabel. Eu e tu: a construção do sujeito no discurso médico. Brasília: Thesaurus, 2000.

MEYER, Dagmar Estermann. Gênero e educação: teoria e política. In: LOURO, G. L.; FELIPE, J.; GOELLNER, S. V. (organizadoras). Corpo, gênero e sexualidade: um debate contemporâneo na educação. 9. ed. Petrópolis, RJ: Vozes, 2013.

OTTONI, Maria Aparecida Resende. As representações identitárias de gênero no humor sexista. In: OTTONI, M. A. R, LIMA, M. C. de (Org.). Discursos, identidades e letramentos - abordagens da Análise de Discurso Crítica. São Paulo: Cortez, 2014. 
SAFFIOTI, Heleieth. A mulber na sociedade de classes: mito e realidade. São Paulo: Expressão popular, 2013.

SCOTT, Joan. Gênero: uma categoria útil de análise histórica. Educação e Realidade, Porto Alegre, v. 16, n. 2, p. 5-22, 1990.

SCOTT, Joan. Prefácio a gender and politics of history. Cadernos Pagu, n. 3 (Desacordos, desamores e diferenças), p. 11-27, 1994.

SCOTT, Joan. La citoyenne paradoxale: lês féministes françaises et lês droits de l’homme. Paris: Albin Michel, 1998.

THOMPSON, John Brookshire. Ideologia e cultura moderna: teoria social crítica na era dos meios de comunicação de massa. Trad. (Coord.) Pedrinho A. Guareschi. Petrópolis: Vozes, 2002.

VAN DIJK, Teun. A. Discurso e Poder. São Paulo: Contexto, 2015.

VIEIRA, Viviane; RESENDE, Viviane de Melo. Análise de Discurso (para a) Crítica: O texto como material de pesquisa. 2.ed. Campinas, SP: Pontes Editores, 2016.

Recebido: 29/10/2020

Aceito: 9/3/2021

Publicado: 26/3/2021 